\title{
Caimi, Mario (coord.), Diccionario de la filosofía crítica kantiana
}

Matías Oroño

\section{OpenEdition}

\section{Journals}

Edición electrónica

URL: http://journals.openedition.org/ref/746

DOI: $10.4000 /$ ref.746

ISSN: 2258-014X

Editor

EuroPhilosophie Editions

Referencia electrónica

Matías Oroño, "Caimi, Mario (coord.), Diccionario de la filosofía crítica kantiana », Revista de Estud(i)os sobre Fichte [En línea], 14 | 2017, Publicado el 01 junio 2017, consultado el 23 septiembre 2020. URL http://journals.openedition.org/ref/746 ; DOI : https://doi.org/10.4000/ref.746

Este documento fue generado automáticamente el 23 septiembre 2020

(C) EuroPhilosophie 


\title{
Caimi, Mario (coord.), Diccionario de la filosofía crítica kantiana
}

\author{
Matías Oroño
}

\section{REFERENCIA}

Caimi, M. (coord.) Diccionario de la filosofía crítica kantiana, Ciudad Autónoma de Buenos Aires: Colihue, 2017, 507 pp., ISBN 9789505634507

1 El estudio de la filosofía crítica de Kant supone la utilización de un vocabulario técnico preciso que en general dista del significado que ciertos términos adquieren en nuestro uso coloquial del lenguaje. Asimismo, en el criticismo kantiano encontramos una peculiar resignificación de muchos conceptos centrales de la tradición filosófica. A ello se suma una dificultad adicional, a saber: al interior del legado del filósofo prusiano un mismo término puede adquirir diferentes significados o matices, incluso dentro de una misma obra. Por estos motivos, si se aspira a alcanzar un conocimiento libre de prejuicios sobre el pensamiento crítico kantiano, es imprescindible contar con léxicos elaborados por especialistas en la filosofía de Kant. Se trata de un requerimiento que ya emerge en el campo de la investigación llevada a cabo en la lengua originaria del autor. Ahora bien, esta exigencia cobra una importancia quizás mayor dentro del ámbito de los estudios sobre Kant en español. El Diccionario de la filosofía crítica kantiana, recientemente publicado por la editorial Colihue, permite suplir esta apremiante necesidad. Nos encontramos ante el resultado de un arduo trabajo de investigación que fue llevado a cabo durante más de una década. Gracias a la labor de un grupo de reconocidos especialistas en filosofía moderna -conformado por Mario Caimi, Ileana Beade, José González Ríos, Macarena Marey, Fernando Moledo, Mariela Paolucci, Hernán Pringe y Marcos Thisted- tenemos acceso hoy a esta valiosísima obra sin precedentes en la lengua española. Un importante punto de partida en la realización de este léxico sobre la filosofía crítica kantiana lo constituye la inmensa obra del lexicógrafo Georg Samuel Albert Mellin: Encyclopädisches Wörterbuch der kritischen Philosophie, once tomos, Jena y Leipzig, 1796-1802. Otro significativo punto de referencia 
en la elaboración de este vocabulario en español lo encontramos en el diccionario kantiano de Rudolf Eisler: Kant Lexikon. Nachschlagewerk zu Kants sämtlichen Schriften, Briefen und handschriftlichem Nachlass, Hildesheim, Olms, (1930) 1984. Asimismo, en la elaboración de este léxico kantiano en lengua española los autores se han servido de la versión electrónica de los textos de Kant editada por Karsten Worm y Susanne Boeck: Kant im Kontext III. 2da. ed. Berlín 2009 - Release (XP/Vista) 6/2009.

2 Si bien los léxicos en lengua alemana antes mencionados constituyen antecedentes cruciales de esta obra, el Diccionario de la filosofía crítica kantiana no consiste en una mera traducción o resumen de dichas obras. Cada una de las entradas que presenta el reciente léxico en español ha sido elaborada de manera independiente y en ellas se reflejan las investigaciones propias que los autores han realizado sobre el significado de los términos que dan cuerpo a la filosofía crítica de Kant. Además, se han incorporado diversas definiciones que no estaban presentes en los respectivos vocabularios que fueron consultados. Algunas de estas novedades se encuentran en entradas como Afección, Barco-reloj, Historia y Mujer.

El diccionario que aquí se comenta ofrece más de 850 entradas. Cada uno de los lemas está acompañado por el correspondiente término en alemán, junto con una traducción al latín, al francés, al italiano y al portugués. Para indicar los correspondientes términos en alemán se ha seguido la ortografía de Mellin y en algunos casos se ha añadido la palabra escrita según las reglas actuales de la ortografía alemana. Las definiciones ofrecidas constituyen verdaderas piezas aclaratorias sobre la filosofía crítica de Kant, pues en muchos casos se indican las diferentes acepciones que un término adopta en distintos contextos de la obra del filósofo de Königsberg. A modo de ejemplo, la entrada Cantidad rescata catorce sentidos del término en cuestión. Asimismo, son sumamente abundantes y fructíferas las remisiones a otras entradas presentes en el léxico. Para continuar con el ejemplo de la entrada Cantidad, allí se indican once referencias a otros lemas, a saber: Axioma, Anticipaciones, Grado, Limitaciones, Magnitud, Medición, Unidad, Pluralidad, Totalidad, Cantidades continuas, Cantidad del mundo. Este aspecto del vocabulario logra enfatizar la riqueza y la complejidad del pensamiento de Kant y al mismo tiempo destaca la imposibilidad de comprender cabalmente el significado de un término sin aludir a otros conceptos presentes en la filosofía crítica kantiana. Al final de cada entrada los lectores pueden hallar indicaciones bibliográficas sobre algunos textos de Kant donde se encuentra el término en cuestión. Si bien estas referencias no pretenden ser exhaustivas, constituyen una gran ayuda para el investigador que intenta comprender el pensamiento kantiano a partir de su propia letra.

4 Tal como es anticipado en el título de este diccionario, los términos versan sobre la filosofía crítica kantiana. No obstante, también se ofrecen explicaciones sobre ideas que pertenecen a lo que suele denominarse período pre-crítico del pensamiento de Kant. A modo de ejemplo, en la entrada Sublime encontramos no sólo referencias a sentidos exclusivamente críticos, sino a lo sublime terrorífico (Schreckhafterhabene) que aparece en un escrito del año 1764. Asimismo, el diccionario ofrece la entrada Terremoto, cuyas indicaciones bibliográficas remiten a diversos textos del año 1756. También es posible hallar referencias a obras pertenecientes al último período de la filosofía de Kant. Un ejemplo de este tipo de indicaciones se puede leer en la entrada Movimiento, la cual contiene diversas referencias al Opus Postumum. Estas breves indicaciones permiten subrayar que el Diccionario de la filosofía crítica kantiana no se limita a un particular 
período del filósofo, sino que permite obtener una visión global de los términos que se encuentran en las diversas obras de Kant.

5 Por último, es importante destacar que este léxico en lengua española aborda de manera equilibrada términos kantianos de las distintas áreas de su pensamiento. De este modo, el Diccionario de la filosofía crítica kantiana constituye una valiosa herramienta para cualquier estudioso de la obra de Kant, pues allí se recogen lemas referidos a temas tan variados como la metafísica, la teoría del conocimiento, la moral, la estética, la teleología, la política, la historia, el derecho, la antropología y la pedagogía, entre otros. Esta diversidad de tópicos da cuenta de la riqueza y originalidad del pensamiento de Kant. Asimismo, el léxico recupera términos referidos a cuestiones tan interesantes como la propia concepción kantiana sobre la teoría de los vientos, la química, la vía láctea y los distintos tipos de movimiento. De esta manera, el Diccionario de la filosofía crítica kantiana es una valiosa herramienta tanto para el estudioso de cuestiones netamente filosóficas, como para el historiador de la ciencia y de las ideas.

\section{AUTORES}

\section{MATÍAS OROÑO}

Universidad de Buenos Aires/CONICET 